\title{
Is Butterfly Effect in the Journal of the Korean Academy of Child and Adolescent Psychiatry?
}

\author{
Geon Ho Bahn \\ Editor-in-Chief, Korean Academy of Child and Adolescent Psychiatry
}

\section{우리 학회지에도 나비효과 있다?}

반 건 호

대한소아청소년정신의학회 편집위원장

2016년부터 학회지 편집을 맡게 되어 걱정이 많았습니다만, 위원들의 헌신적 참여와 회원들의 도움으로 연구재단 등재지 심사도 통과하였고, 이제 4호를 발간합니다. 이번 호의 첫 논 문은 특별원고로 주의력결핍 과잉행동장애(ADHD) 중개연구 팀의 이수민 등이 보고하는 '주의력결핍 과잉행동장애 진단 및 치료: $\mathrm{ADHD}$ 중개연구센터 가이드라인'입니다. 올해 9월 성인 $\mathrm{ADHD}$ 약물치료에 대한 건강보험 적용이 발표되면서 $\mathrm{ADHD}$ 치료에 대한 관심과 함께 오남용에 대한 우려가 늘고 있는 현 실에서 매우 의미 있는 자료가 될 것으로 기대됩니다. 권호장 등은 종설 '아동기 주의력결핍 과잉행동장애의 유해환경인자' 에서 $\mathrm{ADHD}$ 발병기전 관련 인자들에 대해 폭넓게 검토하였 습니다. 이미선 등은 '재난 후 소아청소년의 정신사회적 개입: 체계적 문헌고철(1991 2015)'에서 1991년부터 2015년까지 25 년에 걸친 광범위한 자료를 분석하였고, 요약 내용을 표를 통 해 잘 정리하였습니다.

안인영 등은 교육부, 보건복지부, 질병관리본부에서 해마다 실시하는 '청소년 건강행태 온라인 조사' 2014년 자료를 통해 '다문화가정 청소년과 한국문화가정 청소년의 정서 특성'을 비교 연구하였습니다. 최근 늘고 있는 다문화가정 자료를 우리 나라 일반 가정 아이들 자료와 비교한 소중한 자료입니다. 구 민제 등은 '한국 웩슬러 아동 지능검사-4판(K-WISC-IV)에 서 일반능력 지표(GAI)의 임상적 유용성: 주의력결핍 과잉행 동장애 아동을 대상으로'에서 $\mathrm{ADHD}$ 아이들의 지능검사에서 소검사 차이를 분석하였습니다. 반건호는 서평 'In a different key: The story of autism'을 통해 언론인이 쓴 자폐증의 역사 를 소개하였습니다. 2016년 초 발간된 이 책에는 동료 의료인

This is an Open Access article distributed under the terms of the Creative Commons Attribution Non-Commercial License (http://creativecommons.org/licenses/by-nc/3.0) which permits unrestricted non-commercial use, distribution, and reproduction in any medium, provided the original work is properly cited.
으로서 부끄러운 이야기도 있고, 환아의 가족들이 자폐를 가 진 아이들이 학교와 사회에서 떳떳해질 수 있도록 노력한 투 쟁의 역사도 담겨 있습니다. 자폐증을 진단하고 치료하는 정 신과 의사들이 꼭 알아주었으면 하는 과거이자, 미래의 숙제 이기도 합니다.

편집위원회에서는 학회 이사진의 예산지원을 받아 새롭게 학술지 누리집과 온라인 투고 시스템을 구축하기 시작하였고, 12월이 끝나기 전에 시범가동에 들어갑니다. 누리집이 이사하 고 온라인 투고 시스템이 새롭게 작동하지만 홈페이지 주소는 이전과 같습니다(http://www.jkacap.org/main.html). 새 누리 집은 향후 Pubmed Central, SCI, SCOPUS 등 해외 학술지 등 록 준비를 위한 기초 단계로 영문으로만 표기합니다. 물론 한 글 논문을 검색하거나 투고하는 데 문제는 없습니다. 이에 맞 추어 학회지 내부 디자인도 일부 변화를 주었습니다.

이전에 공지했던 것처럼 학회지 출간일정이 바뀝니다. 올해 까지는 3, 6, 9, 12월 말일에 발행되었으나, 2017년 28권부터는 $1,4,7,10$ 월 1 일자로 발간할 예정입니다. 변화의 가장 큰 이유 는 독자들에게 좋은 자료를 더 빨리 제공하고, 그렇게 함으로 써 인용기회도 늘리고자 함입니다. 해외 유력 포탈 진입을 위 해 1월호와 7월호는 영어논문만을 게재할 예정입니다. 큰 변 화를 위한 노력과 수고를 아끼지 않는 편집위원들의 노고에 다시 한 번 감사의 마음을 전합니다. 회원 여러분께서도 우리 학회지를 아끼고 사랑해 주십시오. 방법은 간단합니다. 시간 날 때마다 학회지 누리집 홈페이지에 들러서 한 번 더 '클릭' 하시고, 부디 좋은 논문 많이 투고해주시고, 다른 학술지에 투고하는 논문에 우리 학회지에 실린 논문을 한 편이라도 인 용해 주시면 됩니다. 회원 개개인의 '클릭' 한 번이 우리 학회 지 미래에 '나비효과'를 만들어 낼 것입니다. 